a parent as one who develops it at a later age? I think there is not a doubt as to the answer to be given; those who become insane before twenty-five, even if they recover, are far less likely to become parents than those who become insane at late agesmany, indeed, of them, considering the high deathrate of the insane, will die before they could become parents of large families. Now Dr. Mott took 508 pairs of parents and offspring, "collected from the records of 464 insane parents whose 500 insane offspring had also been resident in the County Council Asylums," and ascertained the age of first attack. As at present advised, it seems to me that his data must indicate a most marked antedating of disease in the offspring, but an antedating which is wholly spurious. There is, I think, a further grievous fallacy involved in this method of considering the problem; but before discussing that I should like to see if my criticism of this method of approaching the problem of antedating can be met. KARL PEARson.

Biometric Laboratory, University College, London, November $i r$.

\section{Is the Earth Shrinking?}

I HAVE carefully looked at this question from every point of view which presented itself to me, and doubt very much whether any direct evidence will ever be forthcoming on this subject, unless it should one day be established that the changes of magnetic declination are associated with a slight difference of rotation between the core of the earth and its crust, for such a movement would have to be explained by a difference of rate of contraction between the two.

The foldings and crackings of the earth's surface have been attributed to variations in the rate of cooling of the earth. Thus whenever this rate is accelerated, the surface cools faster than the core, and should crack like a drying ball of clay; whenever the cooling rate is diminishing, as assumed by Lord Kelvin, the core should shrink faster than the skin, like a drying apple, and folding should occur. But to my mind, as recently explained in "Unity in Nature," such effects would be entirely masked by such foldings and crackings as are slowly progressing even to-day, for the sediment which is being constantly deposited on the floors of the oceans must cause the underlying strata to grow warmer and to expand in every direction, resulting in slight local risings, which are most marked near the mouths of large rivers, and in distant bulgings and foldings of the weakest lines of the earth's crust, which are the mountain ranges. On the other hand, the gradual wearing away of the surfaces of the continents and mountain ranges must cause the underlying strata to cool, to shrink, and to crack. This suggestion would certainly more than account for all the foldings, faults, and cracks to be found in the earth's crust, even if a considerabie allowance be made for those cases in which the expansions and contractions occur in the same direction, and partly balance each other.

\section{E. Stromeyer.}

"Lancefield," West Didsbury, November 7.

\section{THE HARDNESS OF COINS.}

$\mathrm{H}$ ARDNESS is a word which is used in various senses. In dealing with metals, it sometimes means the cutting or scratching hardness, but is more often defined briefly as the resistance to permanent deformation, a property which is of great importance to all users of metals. It is this kind of hardness with which those

No. 2247 , VOL. 90] engaged in minting are chiefly concerned. When a blank is struck in a coining press, the metal is compressed and at the same time forced to flow into the recesses of the dies, and the ease with which this can be done depends on the amount of resistance offered by the metal to a force momentarily applied and tending to deform it. The hardness should therefore be measured by the effects of a sudden blow, and falling-weight machines, such as Shore's scleroscope, offer a ready means of doing this.

The hardness numbers given below are scleroscope readings, about which it may be said that a piece of metal giving a higher reading is certainly harder than a piece of similar metal giving a lower reading, but that the readings cannot be taken as proportional to the hardness, except as a rough approximation. It cannot be admitted, for example, that a specimen with a hardness number of 40 is exactly twice as hard as one with a hardness number of 20 .

The application of hardness tests to the coins of the realm has resulted in some curious and interesting data being obtained. ${ }^{1}$ It is found, naturally enough, that the blow of a coining press does not raise soft metal to a state of maximum hardness. A sovereign blank after annealing has a surface hardness of 25.5 , and this is raised to $5^{-53}$ on being struck in an ordinary press, the maximum hardness of standard gold being about 76. Silver coins of similar size are hardened to much the same extent; but while sixpences, for example, have a hardness number of about $5^{\circ}$, florins are only 37 . These are the hardnesses of the "table" or flat portions of the coins, but the raised portions of the designs are much softer, especially the highest parts of large thick coins in high relief. Thus in George V. florins the centre of the effigy has a hardness of only 31 , that of the annealed blank from which the coin is struck being $277^{\circ}$. Such coins will evidently wear very differently from coins made in low relief, such as the modern French coins, in which the surface hardness is higher and more uniform.

The hardness of the surface of coins, however, differs widely from that of the interior. The force of the blow seems to be expended chiefly on the surface layers. When these are carefully removed, the hardness of the underlying metal is found to be considerably less. The hardness rapidly falls off with depth, and near the centre even sixpences are almost as soft as annealed silver. Old worn coins are similarly soft.

It is clear, therefore, that a freshly-minted coin has a hard skin and a soft core, and that after the removal of the skin by wear, the loss of weight in circulation will proceed very much as though the coin had been annealed before it was issued. That this is a matter of some importance is illustrated by the fact that the loss by wear of the coinage, which falls on the State, amounts to 3o,ool. per annum for gold, and somewhat more for silver.

Annealing, one of the oldest processes prac1 Memorandum on "The Hardness of Coins," 42nd Annual Report of the Deputy Mastez of the Mint, rgri, pp. roy-rrz. 